\title{
Teknik Instruksional Pertanyaan Guru di Tahap Searching for the Theoritical Background of the Driving Question pada Project Based Learning untuk Meningkatkan Skor Pattern Concept Map
}

\author{
Instructional Techniques Teacher's Question on Searching for the \\ Theoritical Background of the Driving Question of Project Based Learning \\ to Increase Pattern Concept Map Score
}

\author{
Fahma Auliya Dewi ${ }^{1, ~}$, , Sri Widoretno ${ }^{2}$, Alanindra Saputra ${ }^{3}$ \\ 1,2,3 Universitas Sebelas Maret, Jalan Ir. Sutami No. 36A, Surakarta, Indonesia \\ *Corresponding author: sriwidoretno@staff.uns.ac.id
}

\begin{abstract}
The aim of the study was to calculate the score pattern on the concept map (CM) of the students by applying instructional instruction technique of teacher in searching for the theoretical background of the driving question on project based learning. The subjects were 32 high school students. The research is a classroom action research with research procedure including: planning to prepare RPP and its completeness, implementation on activity of action, observation to calculate CM pattern score and reflection for next action. Triangulation validation test includes: verification of conformity of CM pattern score and documentation based on expert pattern CM and interview to represent learners' skill structure. Reduction is done to select the completeness of data, presenting the data and drawing conclusions based on the complete data pattern. Data analysis with qualitative descriptive. The results showed that the pattern score based on the expert pattern of CM on precycle was obtained from $40 \%$ $-60 \%$ range with $46,875 \%$ of total learner got score below average and $0 \%$ above average. Cycle I obtained a score range of $40 \%-100 \%$ with $9.375 \%$ showing scores below average and $43.75 \%$ above average. Cycle II obtained a score range of $40 \%-80 \%$ with $15.625 \%$ indicating scores below average and $12.5 \%$ above average, thus the instructional technique question in the searching phase for the theoretical background of the driving question project based learning increases the score pattern CM both individual and classical.
\end{abstract}

Keywords: Instructional technique, concept map, valid relationship, project-based learning

\section{PENDAHULUAN}

Concept map (CM) merupakan diagram yang merepresentasikan pemahaman peserta didik (Villalon \& Calvo, 2011) dalam bentuk hubungan dan pemetaan konsep (Hidayati, dkk., 2018). CM terdiri dari berbagai komponen yaitu valid relationship, crosslink, hierarki, branching, example dan pattern (Kharatmal \& Nagarjuna, 2006). Komponen pattern $(P)$ merupakan representasi dari kumpulan konsep (Hidayati, dkk., 2018), sehingga menunjukkan struktur pengetahuan yang dimiliki peserta didik (Hung \& Lin, 2015).

Struktur pengetahuan peserta didik merepresentasikan hubungan antara pengetahuan yang sudah dimiliki dan pengetahuan yang belum dimiliki peserta didik (Amadieu, dkk., 2009) yang terukur melalui skor $P$ pada $C M$. $C M$ merupakan teknik instruksional (Tribuzi, 2015) dan assessment (Kinchin, 2011; Trumpower \& Sarwar, 2010) berupa produk pembelajaran yang dikonstruk peserta didik diakhir pembelajaran (Hay, 2007), namun hasil observasi menunjukkan $C M$ belum pernah digunakan sebagai produk pembelajaran, sehingga $P$ yang merupakan struktur pengetahuan belum tervisualisasi.

$P$ terepresentasikan dari $\mathrm{CM}$ yang dibuat oleh peserta didik sebagai produk pembelajaran (Hay, 2007). Produk dihasilkan melalui serangkaian tahapan mulai dari merencanakan, pencarian dasar teori, diskusi, menganalisis, mengevaluasi hingga menyimpulkan yang dilakukan dalam proses pembelajaran (Tamim \& Grant, 2013). Model pembelajaran yang mempunyai serangkaian tahapan tersebut yaitu project based learning (PjBL) (Dole, Bloom, \& Kowalske, 2016).

$P j B L$ merupakan pembelajaran berbasis proyek yang mengacu pada filosofi kontruktivisme sehingga mengakomodasi kegiatan penyelidikan dan penemuan konsep (Shofatun, Ibrahim, \& Wasis, 2016). Model pembelajaran ini mempunyai serangkaian tahapan: 1) planning an investigation process according to driving question, 2) searching for the theoretical 
background of the driving question, 3) presenting that theoretical background to class and discussion about the issue, 4) deciding the study group, the way of collecting data and data analysis, 5) evaluating data, arriving a conclusion, presenting the project in class as preferred and discussion (Turgut, 2008). PjBL mengakomodasi peserta didik untuk mengkonstruk pengetahuan secara mandiri dalam menyelesaikan masalah (Bagheri, dkk., 2013).

Hasil observasi mengenai komponen $P$ pada $C M$ peserta didik dengan penerapan pembelajaran $P j B L$ menunjukkan rata-rata skor $46.875 \%$ dari total skor $100 \%$. Skor $P$ pada $C M$ peserta didik menunjukkan rentang 40\%-60\%, dengan demikian pembelajaran project based learning secara murni menunjukkan bahwa skor $P$ masih kurang optimal. Optimalisasi model pembelajaran $P j B L$ dengan produk $C M$ dilakukan dengan adanya penambahan teknik instruksional.

Teknik instruksional merupakan pertolongan guru berupa komunikasi berisikan bimbingan detail yang salah satunya yaitu berupa pertanyaan (Mayer \& Alexander, 2010). Teknik instruksional digunakan sebagai panduan sistematis untuk membantu peserta didik dalam meningkatkan kinerjanya dalam pembelajaran (Akdeniz, 2016) dan memfokuskan peserta didik dalam mempelajari suatu konsep (AlZahrani \& Al-Bargi, 2017). Teknik instruksional mampu diterapkan di semua tahap PjBL (Gustafson \& Branch, 2002), karena mengakomodasi peserta didik untuk mengumpulkan informasi sebagai pendukung perencanaan penyelidikan (Turgut, 2008) pada tahap searching for the theoretical background of the driving question pada project based learning.

Tahap searching for the theoretical background of the driving question pada project based learning dalam mengumpulkan informasi seringkali menimbulkan miskonsepsi karena peserta didik kesulitan dalam menemukan konsep yang benar dari banyaknya referensi (Sockalingam \& Schmidt, 2011). Teknik instruksional berupa pertanyaan merupakan cara untuk membantu peserta didik dalam menemukan jawaban (Wright, dkk., 2012), berupa konsep untuk dikonstruk oleh peserta didik sebagai proses berfikir (Chin \& Osborne, 2008). Jawaban yang ditemukan peserta didik diorganisir berupa daftar jawaban, bertujuan untuk memudahkan peserta didik mengorganisir konsep (Sher, dkk., 2011), yang tervisualisasi pada $P$ dalam $C M$ (Kinchin, 2012). Teknik instruksional pertanyaan guru pada tahap searching for the theoretical background of the driving question diasumsikan mampu meningkatkan skor $P$ pada $C M$ peserta didik, dengan demikian tujuan penelitian yaitu meningkatkan skor $P$ peserta didik dengan menerapkan teknik instruksional pertanyaan guru pada tahap searching for the theoretical background of the driving question pada pembelajaran project based learning.

\section{METODE PENELITIAN}

Subjek penelitian adalah peserta didik kelas X MIPA dengan jumlah peserta didik sebanyak 32. Pemilihan subjek didasarkan pada permasalahan yang teridentifikasi pada kegiatan observasi proses pembelajaran yang berkaitan dengan skor $P$ pada $C M$.

Penelitian merupakan penelitian tindakan kelas dengan 2 siklus yang terdiri dari tahap perencanaan, pelaksanaan tindakan dan refleksi (Kemmis dan Mc Taggart dalam Darmawati, 2016)). Penelitian dengan menerapkan teknik instruksional berupa pertanyaan guru di tahap searching for the theoretical background of the driving question pada project based learning. Materi yang digunakan pada prasiklus, siklus I, dan siklus II berturut-turut yaitu Musci, Anthocerophyta, dan Marchantiophyta.

Data penelitian berupa skor $P$ pada $C M$ peserta didik dengan data pendukung keterlaksanaan sintak penerapan teknik instruksional di tahap searching for the theoretical background of the driving question, wawancara dan dokumentasi. Uji validitas data penelitian menggunakan teknik triangulasi data (Wiliam Wiersma dalam Bachri, 2010)). Analisis data penelitian dilakukan dengan teknik analisis deskriptif kualitatif yang terdiri dari reduksi data, penyajian data dan penarikan kesimpulan berdasarkan skor $P$ yang lengkap (Miles dan Huberman (1994) dalam Gumilang (2016)). Analisis perhitungan skor $P$ pada $C M$ sesuai dengan expert $C M$. Contoh $C M$ menurut Novak \& Gowin (1984) ditunjukkan pada Gambar 1.

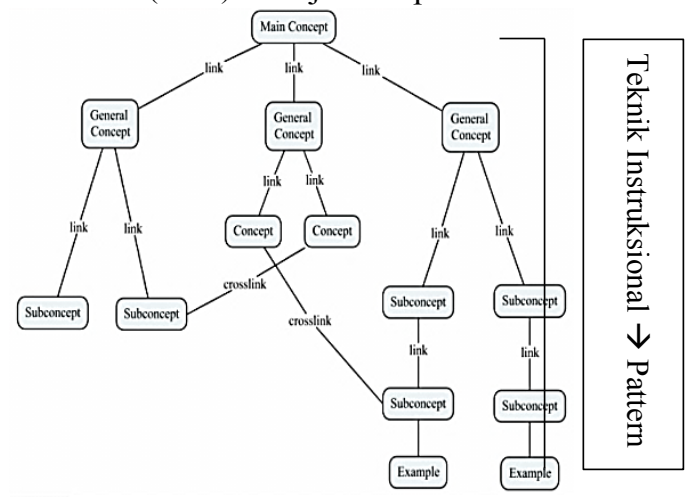

Gambar 1. Contoh $C M$ menurut Novak \& Gowin (1984)

Gambar 1 menunjukkan contoh $C M$. Penilaian skor $P$ pada $C M$ menurut Novak \& Gowin (1984) disajikan pada Tabel 1 .

Tabel 1. Rubrik penilaian skor $P$ pada $C M$

\begin{tabular}{cccc}
\hline No. & Indikator & Skor & $\begin{array}{c}\text { Skor Expert } \\
C M\end{array}$ \\
\hline 1. & Pattern & Maks. 5 & 5 poin \\
\hline & Jumlah Skor & & 5 poin \\
\hline
\end{tabular}

Sumber: Novak \& Gowin (1984)

\section{HASIL DAN PEMBAHASAN}

\section{Hasil}

Prasiklus dilakukan melalui kegiatan pembelajaran $P j B L$ di salah satu kelas X MIPA pada materi $M u s c i$ 
mengenai ciri-ciri, metagenesis, klasifikasi, dan peranan. Kegiatan pembelajaran diakhiri dengan penyusunan $C M$. data skor P pada $C M$ peserta didik di kegiatan prasiklus disajikan pada Gambar 2.

\section{Presentase Skor Pattern pada CM Peserta Didik di Prasiklus}

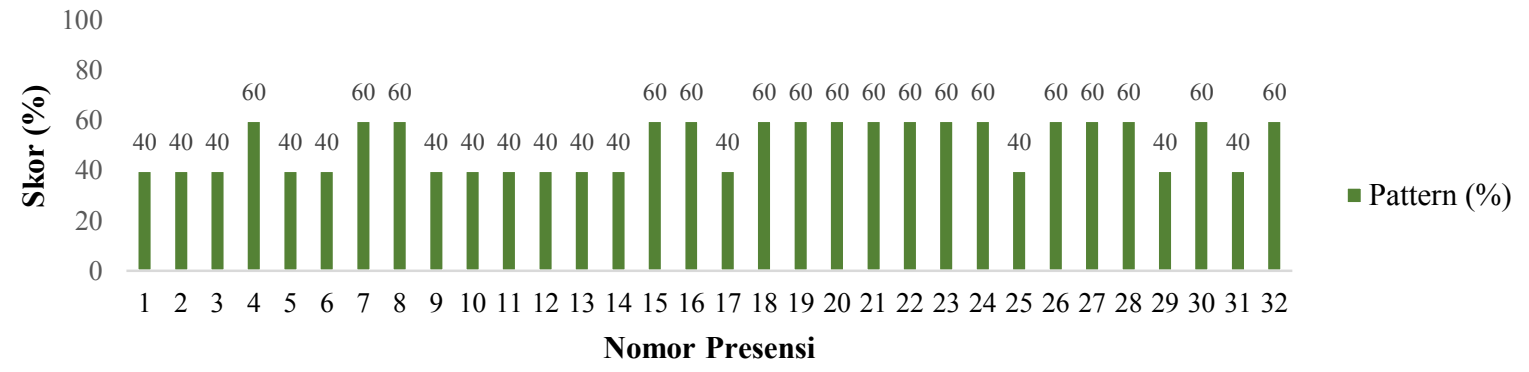

Gambar 2. Presentase Skor $P$ pada $C M$ Peserta Didik di Prasiklus

Hasil skor rata-rata $P$ di prasiklus sebesar $50.625 \%$. Peserta didik yang memperoleh skor $P$ di bawah rata-rata sebesar $46.875 \%$, sementara $0 \%$ dari total peserta didik memperoleh skor $P$ di atas rata-rata, dengan demikian analisis skor $P$ pada $C M$ yang disusun oleh peserta didik di akhir pembelajaran belum optimal.
Kegiatan pembelajaran siklus I menggunakan materi Anthocerophyta mengenai ciri-ciri, metagenesis, klasifikasi, dan peranan, yang diakhiri dengan penyusunan $C M$. Data skor $P$ pada $C M$ peserta didik di siklus I disajikan pada Gambar 3.

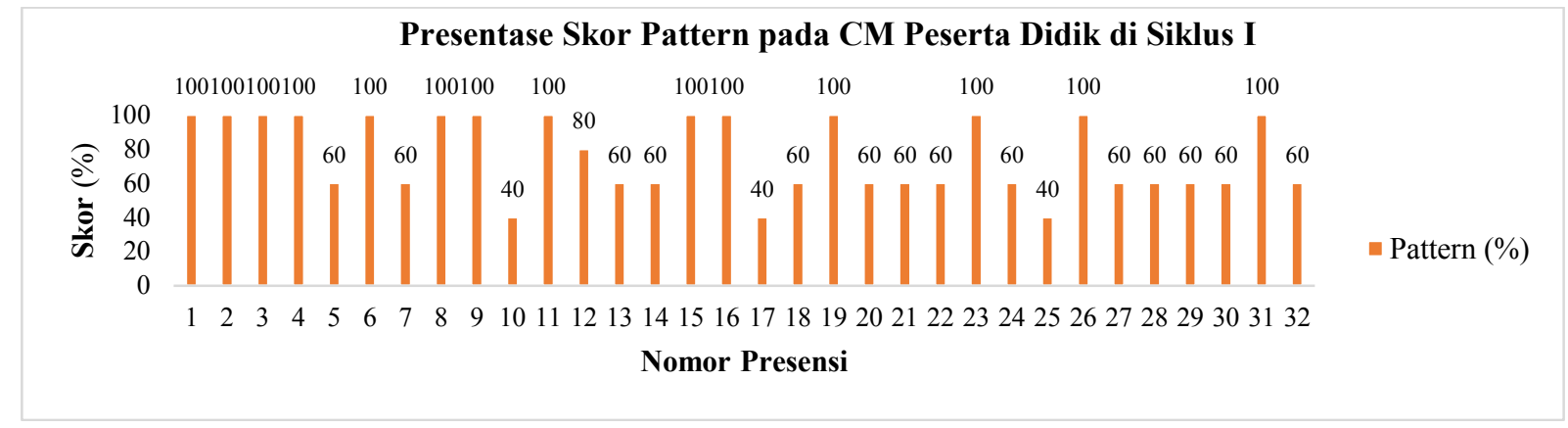

Gambar 3. Presentase Skor P pada CM Peserta Didik di Siklus I

Hasil skor rata-rata $\mathrm{P}$ di siklus I sebesar $76.25 \%$. Peserta didik yang memperoleh skor $\mathrm{P}$ di bawah ratarata sebesar $9.375 \%$, sementara $43.75 \%$ dari total peserta didik memperoleh skor $\mathrm{P}$ di atas rata-rata, dengan demikian analisis skor $\mathrm{P}$ pada $\mathrm{CM}$ yang disusun oleh peserta didik di akhir pembelajaran mengalami peningkatan dari prasiklus ke siklus I.
Siklus II dilaksanakan berdasarkan refleksi yang dilakukan di siklus I. Kegiatan pembelajaran menggunakan materi Marchantiophyta mengenai ciriciri, klasifikasi, metagenesis, dan peranan. Data skor $\mathrm{P}$ pada CM peserta didik di siklus II disajikan pada Gambar 4.

\section{Presentase Skor Pattern pada CM Peserta Didik di Siklus I}

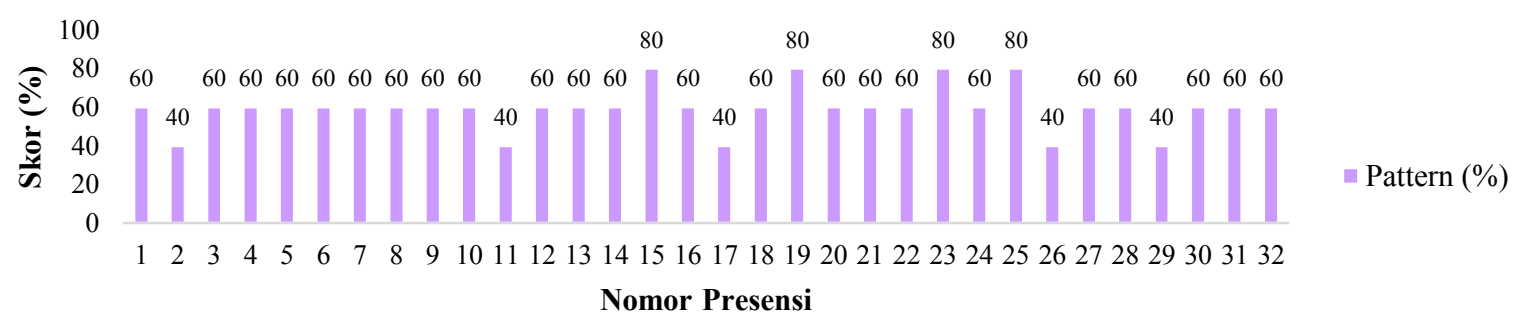

Gambar 4. Presentase Skor $P$ pada CM Peserta Didik di Siklus II 
Hasil skor rata-rata $P$ di siklus II sebesar 59.375\%. Peserta didik yang memperoleh skor $P$ di bawah rata-rata sebesar $15.625 \%$, sementara $12.5 \%$ dari total peserta didik memperoleh skor $P$ di atas rata-rata, dengan demikian analisis skor $P$ pada $C M$ yang disusun oleh peserta didik di akhir pembelajaran mengalami penurunan dari siklus I ke siklus II.

\section{Pembahasan}

Perbandingan hasil tindakan dengan penerapan tekhnik instruksional berupa pertanyaan guru di tahapan searching for the theoretical background of the driving question pada pembelajaran mengalami perubahan yang fluktuatif. Perubahan dilihat dari skor total komponen $P$ pada $C M$ sebesar 50.625\%, 76.25\%, dan 59.375\%. Data perbandingan tiap siklus ditunjukkan pada Gambar 5.

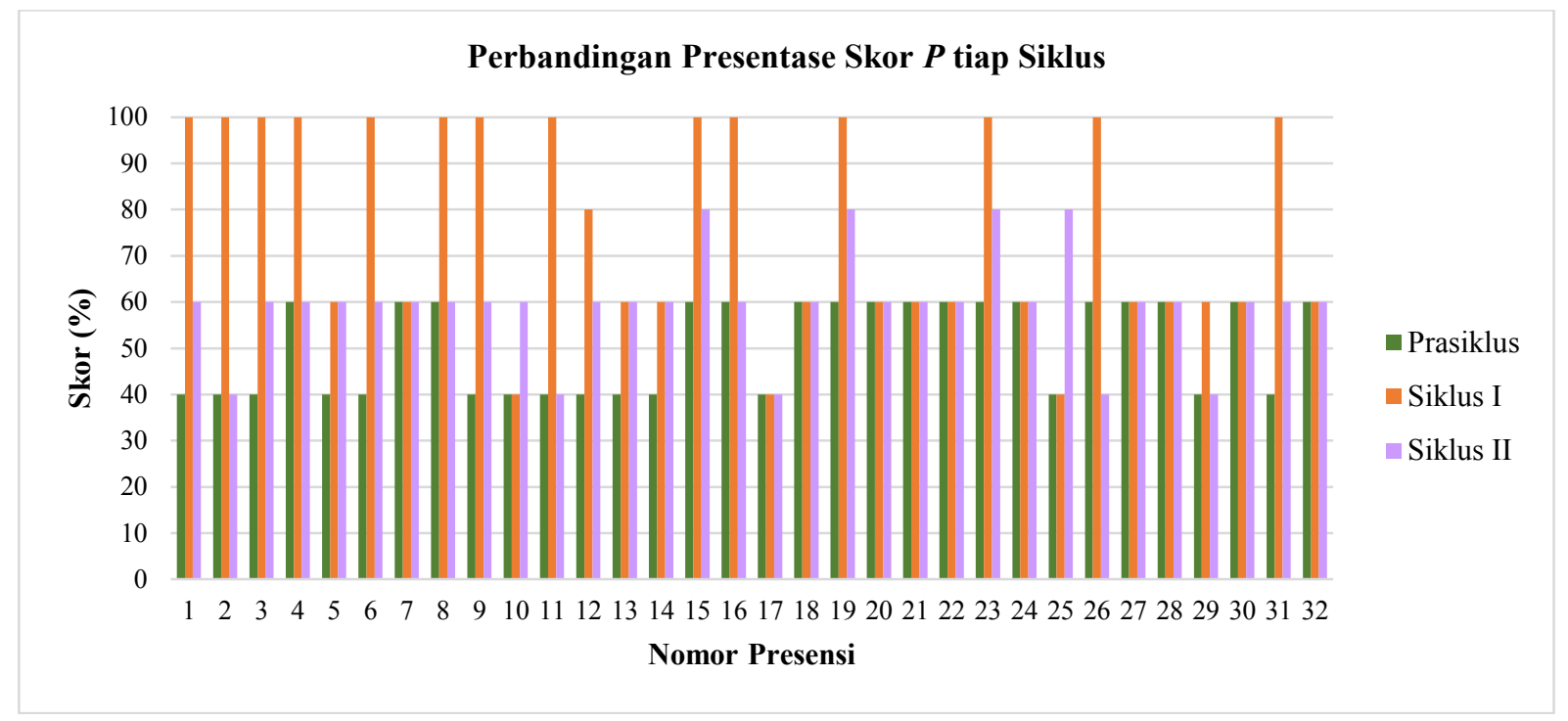

Gambar 5. Perbandingan Skor $P$ pada Setiap Siklus

Skor total komponen $P$ mengalami peningkatan dari prasiklus ke siklus I, kemudian mengalami penurunan dari siklus I ke siklus II. Perubahan yang fluktuatif disebabkan setiap individu memiliki kelebihan dan kekurangan yang spesifik. Skor pada tiap komponen masing-masing peserta didik digolongkan menjadi tiga bagian, dibawah skor ratarata, diantara skor rata-rata dan diatas skor rata-rata.

Komponen $P$ merupakan representasi dari kumpulan konsep (Hidayati, dkk., 2018), sehingga menunjukkan struktur pengetahuan yang dimiliki peserta didik (Hung \& Lin, 2015), namun pada prasiklus $46.875 \%$ dari total peserta didik memperoleh skor dibawah standar, kemudian pada siklus I skor dibawah standar mengalami penurunan menjadi $9.375 \%$, kemudian pada siklus II mengalami peningkatan menjadi $15.625 \%$. $P$ pada prasiklus menunjukkan $53.125 \%$ dari total peserta didik memperoleh skor normal, namun pada siklus I mengalami penurunan menjadi $40.625 \%$, kemudian pada siklus II mengalami peningkatan menjadi $71.875 \%$. $P$ pada prasiklus tidak terdapat peserta didik yang memperoleh skor diatas standar, kemudian pada siklus I mengalami peningkatan menjadi $43.75 \%$, namun pada siklus II mengalami penurunan menjadi $12.5 \%$, dengan demikian komponen $P$ mengalami peningkatan jumlah peserta didik dari prasiklus ke siklus I, namun mengalami penurunan jumlah peserta didik dari siklus I ke siklus II.
Peningkatan pada komponen $P$ dalam $C M$ disebabkan adanya penambahan teknik instruksional berupa pertanyaan yang diterapkan pada tahap searching for the theoretical background of the driving question di PjBL. Teknik instruksional berupa pertanyaan di tahap searching for the theoretical background of the driving question menjadi petunjuk bagi peserta didik untuk mencari informasi pada topik yang benar, sehingga tidak terjadi miskonsepsi (Sockalingam \& Schmidt, 2011). Pembelajaran yang tidak terjadi miskonsepsi bertujuan supaya peserta didik mencapai proses kognitif yang lebih bermakna, tidak hanya sekedar menemukan namun juga mengkonstruk informasi yang belum diketahui peserta didik menjadi pengetahuan yang lebih bermakna ( $\mathrm{Wu}$, Chen, \& Hou, 2016).

Informasi yang dikonstruk oleh peserta didik digambarkan dalam bentuk $P$ pada $C M$. $P$ merupakan gabungan struktur konsep pengetahuan yang digambarkan dengan konsep yang paling umum berada di paling atas dan semakin menurun menjadi semakin spesifik (Hung \& Lin, 2015). Penggambaran $P$ secara otomatis membentuk struktur susunan pengetahuan yang hierarkis pada $C M$ (Cañas, dkk., 2015).

Komponen $P$ menunjukkan struktur pengetahuan (Afamasaga-Fuata'i, 2004) dan pemahaman yang dimiliki peserta didik (Kinchin, Hay, \& Adams, 2000), dengan demikian penambahan 
teknik instruksional berupa pertanyaan pada tahap searching for the theoretical background of the driving question di PjBL mampu mengembangkan kemampuan mengorganisir konsep untuk mengkonstruk struktur pengetahuan.

Penurunan komponen $P$ dalam perhitungan $\mathrm{CM}$ dari siklus I ke siklus II disebabkan karena materi yang digunakan pada siklus II terlalu kompleks, sehingga manajemen waktu pada peserta didik tidak maksimal. Materi yang terlalu kompleks mengakibatkan motivasi peserta didik menjadi rendah saat pembelajaran (Granito \& Chernobilsky, 2012), sehingga guru membutuhkan lebih banyak waktu untuk memotivasi peserta didik. Waktu yang dihabiskan untuk menstimulasi motivasi peserta didik berdampak pada alokasi waktu yang tidak sesuai dengan Rencana Pelaksanaan Pembelajaran (RPP), serta kurangnya waktu untuk mengkonstruk $C M$ lebih singkat. Alokasi waktu yang kurang optimal mempengaruhi hasil dari tugas yang dikerjakan peserta didik (Nasrullah \& Khan, 2015), sehingga alokasi waktu yang singkat menyebabkan $C M$ yang dibuat oleh peserta didik tidak maksimal.

Alokasi waktu yang singkat saat mengkonstruk $C M$ memiliki dampak yang menyebabkan peserta didik tidak mampu membentuk struktur kognitif yang maksimal. Struktur $C M$ yang maksimal yang dibangun peserta didik adalah struktur yang memetakan konsep umum berada di paling atas, kemudian semakin kebawah menjadi lebih spesifik (Cañas, dkk., 2015).

Pemetaan konsep dilakukan dengan penyederhanaan konsep dan mengaturnya pada kertas untuk mengkonstruk $C M$ (Ajaja, 2013), sehingga membutuhkan waktu yang lama untuk mengkonstruk $C M$ supaya membentuk struktur $C M$ yang maksimal. Waktu yang singkat menyebabkan efisiensi peserta didik dalam membuat $C M$ tidak maksimal, sehingga terjadi penurunan pada $P$ dari siklus I ke siklus II.

Komponen $P$ menunjukkan struktur pengetahuan (Afamasaga-Fuata'i, 2004) dan pemahaman yang dimiliki peserta didik (Kinchin et al., 2000), dengan demikian skor yang meningkat pada $P$ mengindikasikan penerapan teknik instruksional berupa pertanyaan pada tahapan searching for the theoretical background of the driving question di PjBL mampu meningkatkan kemampuan peserta didik dalam mengorganisir konsep untuk mengkonstruk struktur pengetahuan yang sempurna.

\section{SIMPULAN}

Hasil analisis penerapan teknik instruksional pertanyaan di tahap searching for the theoretical background of the driving question meningkatkan skor pattern CM baik individu maupun klasikal.

\section{UCAPAN TERIMAKASIH}

Terimakasih kepada Tuhan Yang Maha Esa yang telah memberikan kekuatan kepada penulis dalam menyelesaikan jurnal ini, Drs. Bagus Nugroho, M.Pd selaku Kepala SMA Negeri 1 Karanganyar, Ika Setyanti, S.Pd selaku Guru Mata Pelajaran Biologi kelas X SMA Negeri 1 Karanganyar, dan semua partisipan dalam penelitian, keluarga, saudara, serta teman-teman yang telah membantu dan mendukung dalam proses penyusunan jurnal ini.

\section{DAFTAR PUSTAKA}

Afamasaga-Fuata'i, K. (2004). Concept Maps \& Vee Diagrams as Tools for Learning New Mathematics Topics. First Int. Conference on Concept Mapping, 1, 13-20. Retrieved from http://eprint.ihmc.us/72/

Ajaja, O. P. (2013). Which strategy best suits biology teaching? Lecturing, concept mapping, cooperative learning or learning cycle? Electronic Journal of Science Education, 17(1). Retrieved from osawaruajaja@yahoo.com

Akdeniz, C. (2016). Instructional Process and Concepts in Theory and Practice.

https://doi.org/10.1007/978-981-10-2519-8

Al-Zahrani, M. Y., \& Al-Bargi, A. (2017). The Impact of Teacher Questioning on Creating Interaction in EFL: A Discourse Analysis. English Language Teaching, 10(6), 135. https://doi.org/10.5539/elt.v10n6p135

Amadieu, F., van Gog, T., Paas, F., Tricot, A., \& Mariné, C. (2009). Effects of prior knowledge and concept-map structure on disorientation, cognitive load, and learning. Learning and Instruction, 19(5), 376-386. https://doi.org/10.1016/j.learninstruc.2009.02.00 5

Bachri, B. S. (2010). Meyakinkan Validitas Data Melalui Triangulasi Pada Penelitian Kualitatif. Teknologi Pendidikan, 10(1), 46-62.

Bagheri, M., Zah, W., Ali, W., Chong, M., Abdullah, B., \& Daud, S. M. (2013). Effects of Projectbased Learning Strategy on Self-directed Learning Skills of Educational Technology Students. Contemporary Educational Technology, 4(1), 15-29.

Cañas, A. J., Novak, J. D., \& Reiska, P. (2015). Knowledge Management \&amp; E-Learning How good is my concept map? Am I a good Cmapper? How good is my concept map? Am I a good Cmapper? Knowledge Management \& ELearning, 7(71), 6-19.

Chin, C., \& Osborne, J. (2008). Students' questions: A potential resource for teaching and learning science. Studies in Science Education, 44(1), 139. https://doi.org/10.1080/03057260701828101

Darmawati. (2016). Penerapan Pendekatan Contextual Teaching and Learning dalam Meningkatkan Hasil Belajar Siswa pada Materi Penjumlahan dan Pengurangan Bentuk Aljabar Kelas VII SMP Negeri 1 Banawa. Jurnal Pendidikan Matematika, 5(1), 94-105.

Dole, S., Bloom, L., \& Kowalske, K. (2016). Transforming pedagogy: Changing perspectives from teacher-centered to learner-centered. Interdisciplinary Journal of Problem-Based Learning, 10(1), 45-58.

https://doi.org/10.7771/1541-5015.1538 
Granito, M., \& Chernobilsky, E. (2012). The Effect of Technology on a Student's Motivation and Knowledge Retention. NERA Conference Proceedings 2012. Retrieved from http://digitalcommons.uconn.edu/nera_2012/17

Gumilang, G.S. (2016). Metode Penelitian Kualitatif dalam Bidang Bimbingan dan Konseling. Jurnal Fokus Konseling. 2(2). 144-159

Gustafson, K. L., \& Branch, R. M. (2002). What is instructional design? Trends and Issues in Instructional Design and Technology. https://doi.org/10.1016/B978-0-12-386531$1.00002-8$

Hay, D. B. (2007). Using concept maps to measure deep, surface and non-learning outcomes. Studies in Higher Education, 32(1), 39-57. https://doi.org/10.1080/03075070601099432

Hidayati, H., Ramli, R., Hamdiyati, Y., Sudargo, F., Redjeki, S., \& Fitriani, A. (2018). Using concept maps to describe undergraduate students' mental model in microbiology course. 4th International Seminar of Mathematics, Science and Computer Science Education, $1013 \quad 01201$. https://doi.org/10.1088/17426596/1013/1/012014

Hung, C.-H., \& Lin, C.-Y. (2015). Using concept mapping to evaluate knowledge structure in problem-based learning. BMC Medical Education, 15(1), 212.

https://doi.org/10.1186/s12909-015-0496-x

Kharatmal, M., \& Nagarjuna, N. (2006). A Proposal to Refine Concept Mapping for Effective Science Learning. Concept Maps: Theory, Methodology, Technology. Proc. of the Second Int. Conference on Concept Mapping., 1, 1-7. Retrieved from http://eprint.ihmc.us/146/

Kinchin, I. M. (2011). Visualising knowledge structures in biology: Discipline, curriculum and student understanding. Journal of Biological Education, 45(4), 183-189.

https://doi.org/10.1080/00219266.2011.598178

Kinchin, I. M. (2012). Concept Mapping and The Fundamental Problem of Moving Between Knowledge Structures. Journal for Educators, Teachers and Trainers, 4(2013), 96-106.

Kinchin, I. M., Hay, D. B., \& Adams, A. (2000). How a qualitative approach to concept map analysis can be used to aid learning by illustrating patterns of conceptual development. Educational Research, 42(1), 43-57. https://doi.org/10.1080/001318800363908

Mayer, R. E., \& Alexander, P. A. (2010). Learning to Write. New York.

https://doi.org/10.4324/9780203839089.ch3

Nasrullah, S., \& Khan, M. S. (2015). The Impact of Time Management on the Students 'Academic Achievements. Journal of Literature, Languages and Linguistics, 11(February), 66-72.

https://doi.org/10.1088/17426596/995/1/012042

Novak, J. D., \& Gowin, D. B. (1984). Learning How to Learn.
Sher, A. A., Mahmood, T. K., Naeem, M. M., \& Hussain, A. D. (2011). Students , Misconceptions in Learning Basic Concept “ Composition of Matter " in Chemistry Ahmed Sher Awan Assistant Professor Department of Science Education Institute of Education and Research University Punjab Lahore Pakistan Dr . Tariq Mahmood Khan As, 1(4), 161-167.

Shofatun, A., Ibrahim, M., \& Wasis. (2016). Pembelajaran Ipa Terpadu Melalui Project Based Learning Dalam Melatihkan Academic, 6(1), 1150-1158.

Sockalingam, N., \& Schmidt, H. G. (2011). Characteristics of Problems for Problem-Based Learning: The Students' Perspective. Interdisciplinary Journal of Problem-Based Learning, 5(1), 3-16.

https://doi.org/10.7771/1541-5015.1135

Tamim, S. R., \& Grant, M. M. (2013). Interdisciplinary Journal of Problem-Based Learning Definitions and Uses: Case Study of Teachers Implementing Project-based Learning Definitions and Uses: Case Study of Teachers Implementing Project-based Learning. Interdisciplinary Journal of Problem-Based Learning, 7(2), 5-16.

https://doi.org/10.7771/1541-5015.1323

Tribuzi, S. B. (2015). Efficacy of Concept Mapping Instructional Techniques to Teach Organizational Structures and Interactions.

Trumpower, D. L., \& Sarwar, G. S. (2010). Formative structural assessment: Using concept maps as assessment for learning. Proceedings of the Fourth International Conference on Concept Mapping, 2(1999), 132-136. Retrieved from http://cmc.ihmc.us/cmc2010papers/cmc2010214.pdf

Turgut, H. (2008). Prospective Science Teachers' Conceptualizations about Project Based Learning. International Journal of Instruction, 1(1), 61-79.

Villalon, J., \& Calvo, R. A. (2011). Concept Maps As Cognitive Visualisations Of Writing Assignments. Educational Technology \& Society, 14(3), 16-27. Retrieved from http://www.academia.edu/465699/Concept map s_as_cognitive_visualisations_of_writing_assig nments

Wright, G., Shumway, S., Terry, R., \& Bartholomew, S. (2012). Analysis of Five Instructional Methods for Teaching Sketchpad to Junior High Students. Journal of Technology Education, 24(1), 54-72.

Wu, S. Y., Chen, S. Y., \& Hou, H. T. (2016). Exploring the interactive patterns of concept map-based online discussion: a sequential analysis of users' operations, cognitive processing, and knowledge construction. Interactive Learning Environments, 24(8), 17781794.

https://doi.org/10.1080/10494820.2015.1057740 